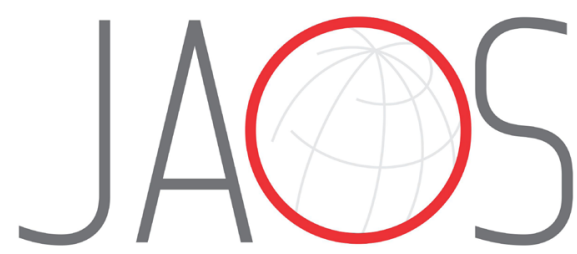
JOURNAL OF APPLIED ORAL SCIENCE

\title{
Complete denture hygiene solutions: antibiofilm activity and effects on physical and mechanical properties of acrylic resin
}

\section{Abstract}

Millena Mangueira ROCHA ${ }^{1}$

Adrianne Moura CARVALHO ${ }^{1}$

Flávia Cristina Targa COIMBRA ${ }^{1}$

Carolina Noronha Ferraz de ARRUDA ${ }^{1}$

Viviane de Cássia OLIVEIRA ${ }^{1}$

Ana Paula MACEDO ${ }^{1}$ iD

Cláudia Helena SILVA-LOVATO ${ }^{1}$

Valéria Oliveira PAGNANO ${ }^{1}$ iD

Helena de Freitas Oliveira

PARANHOS ${ }^{1}$ ID

Submitted: November 3, 2020 Modification: March 15, 2021 Accepted: April 18, 2021
Appropriated denture hygiene is a predictive factor for longevity of rehabilitation treatment and maintenance of the oral mucosal health. Although, disinfectant solutions are commonly used as denture cleansers, the impact of these solutions on acrylic resin-based dentures remain unclear. Objective: To evaluate, in vitro, the antibiofilm activity of complete denture hygiene solutions and their effects on physical and mechanical properties of acrylic resin. Methodology: For antibiofilm activity measurement acrylic resin specimens were contaminated with Candida albicans, Candida glabrata and Streptococcus mutans. After biofilm growth, the specimens were assigned to the hygiene solutions: Distilled water (Control); $0.2 \%$ Sodium hypochlorite (SH); Efferdent Power Clean Crystals (EPC) and 6.25\% Ricinus communis $(\mathrm{RC})$. The viability of microorganisms was evaluated by agar plate counts. In parallel, physical, and mechanical properties of the acrylic resin were evaluated after simulating a 5-year period of daily immersion in the previously mentioned solutions. The changes in surface roughness, color, microhardness, flexural strength, impact strength, sorption and solubility were evaluated. Data were compared by ANOVA followed by the Tukey test or Kruskal-Wallis followed by the Dunn test depending on the distribution $(\alpha=0.05)$. Results: Regarding antibiofilm action, $\mathrm{SH}$ eliminated all microorganisms while EPC and RC exhibited moderate action against $S$. mutans $(p=0.001)$ and $C$. glabrata $(p<0.001)$, respectively. Relative to effects on the physical and mechanical properties of the acrylic resin, $\mathrm{RC}$ led to higher values of color change $(p=0.030)$, hardness $(p<0.001)$, surface roughness $(p=0.006)$ and flexural strength $(p<0.001)$. Moreover, RC induced the highest values of changes in solubility $(p<0.001)$. EPC promoted greater changes in surface morphology, whereas immersion in $\mathrm{SH}$ retained the initial appearance of the acrylic resin surface. All hygiene solutions reduced the impact strength $(p<0.05)$. Conclusion: SH presented the most effective antibiofilm activity. In addition, changes on properties were observed after immersion in RC, which were considered within acceptable limits.

Keywords: Complete denture. Acrylic resin. Biofilm. Properties. Products with antimicrobial action.
Corresponding address: Helena de Freitas Oliveira Paranhos Universidade de São Paulo - Faculdade de Odontologia de Ribeirão Preto - Departamento de Materiais Dentários e Prótese Avenida do Café S/N - 14040-904 Ribeirão Preto - SP - Brasil. Phone: +55 $163315-4031$ e-mail: helenpar@forp.usp.br
${ }^{1}$ Universidade de São Paulo, Faculdade de Odontologia de Ribeirão Preto, Departamento de Materiais Dentários e Prótese, Ribeirão Preto, SP, Brasil. 


\section{Introduction}

The denture biofilm must be removed daily means of proper cleaning, since it can lead to local and systemic diseases. ${ }^{1,2}$ Sodium hypochlorite and alkaline peroxide solutions are widely indicated for denture biofilm control, in short or long-time immersions, either associated with mechanical methods such as brushing, or not. ${ }^{3}$ These solutions must be effective without being deleterious to the materials of which the prosthetic device is made. In addition, the type of denture cleanser, manufacturer's instructions and period of use/immersion must be considered.

In vitro studies have shown the effectiveness of $1 \%$ and $0.5 \%$ sodium hypochlorite, used in different immersion periods, relative to their ability to remove biofilm and antimicrobial action against Candida spp. ${ }^{4-}$ ${ }^{6}$ In vivo studies have confirmed that $1 \%, 0.5 \%$ and $0.25 \%$ sodium hypochlorite solutions were efficacious for removing biofilm from denture surfaces, in addition to exhibiting significant antimicrobial activity against Streptococcus mutans, Candida spp. and gram negatives bacteria. ${ }^{7-11}$ However, adverse effects on acrylic resin-based dentures have been reported after applying $1 \%$ and $0.5 \%$ sodium hypochlorite in routine hygiene practice. ${ }^{12-19}$ Randomized clinical studies have shown the effectiveness of $0.2 \%$ sodium hypochlorite, with reduction in biofilm levels, notable antimicrobial action against Candida spp. and remission of denture stomatitis, without significant changes in color, surface roughness, and flexural strength of the acrylic resinbased dentures. ${ }^{20-22}$ Therefore, this solution should be evaluated against different microorganisms of which the denture biofilm is composed, such as Candida spp. and $S$. mutans, together with its effect on other relevant acrylic resin properties.

Alkaline peroxide solutions have been shown to be effective in short ${ }^{22-30}$ and long ${ }^{19,31}$ periods of immersion. The antimicrobial action of these solutions has been evaluated against monospecies biofilms, composed mainly of C. albicans.4,32,33 As regard adverse effects, changes in color, surface roughness and flexural strength of acrylic resin have been reported; ${ }^{14,16,34}$ therefore, it is important to follow the manufacturer's instructions for better action and prevention of significant effects on prosthetic devices. The effectiveness of Efferdent peroxide-based solution against microorganisms related to local and systemic diseases has been established;27,29 however, the effects on the acrylic resin-based dentures properties have not yet been evaluated. Therefore, new investigations should be conducted, in order to clarify whether Efferdent peroxide-based solution could promote adverse effects on prosthetic devices.

Although Ricinus communis solutions have been used as denture cleansers, $6,7,10,20,35$ scientific data in the literature are controversial, and up to now, no ideal concentration has been established. A $2 \%$ solution showed moderate ability to remove denture biofilm, and effective action in reducing $C$. albicans and $S$. mutans on the surface of a complete denture reliner. ${ }^{7,35}$ A $3.3 \%$ mouthwash resulted in remission of denture stomatitis; however, it was unable to reduce Candida spp. ${ }^{36}$ Solutions at $8 \%$ and $10 \%$ led to a decrease in microbial load of C. albicans, Candida glabrata, and $S$. mutans, and remission of denture stomatitis, with moderate action on biofilm removal. ${ }^{6,10,11,20,21}$ In addition, the deleterious effects of these solutions on acrylic resin-based dentures properties were classified as being clinically acceptable. ${ }^{15,18,21}$ A previous study showed that the minimum inhibitory concentration of $R$. communis necessary to inhibit the growth of microorganisms such as C. albicans and C. glabrata was $6.25 \%,{ }^{22}$ but studies about its safety relative to effects on resin properties have not yet been conducted.

The literature has shown the importance of using chemical cleansers in denture hygiene and the feasibility of using diluted hypochlorite, ${ }^{6-11,20-22}$ peroxide-based solutions ${ }^{19,22,24,26,28,32}$ and $R$. communis solutions $s^{6,7,10,20,22,35}$ in patients' daily hygiene. Thus, studies involving these solutions should be developed, to indicate a safe protocol for patients' health, which do not promote adverse effects on acrylic resinbased dentures. This, in turn, is one of the main factors that will ensure the long-term durability of oral rehabilitation. Therefore, in this study, in vitro analysis was performed to evaluate the antibiofilm activity of $0.2 \%$ sodium hypochlorite, Efferdent peroxide-based solution and $6.25 \% R$. communis solution against monospecies biofilms composed of C. albicans, C. glabrata and S. mutans. In parallel, the effects on physical and mechanical properties of thermally activated acrylic resin were evaluated by simulating an estimated period of use of a complete denture. The null hypothesis was that there would have no difference on both antimicrobial action and effects on properties of acrylic resin regarding the use of the 
cleanser solutions.

\section{Methodology}

\section{Experimental Design}

In this study, the ability of the hygiene solutions to remove $C$. albicans, C. glabrata and $S$. mutans mature biofilm, grown on acrylic resin surface, was evaluated by simulating a single short daily period of immersion. In addition, denture cleanser effects on physical and mechanical properties of acrylic resin were analyzed by simulating a 5-year period of daily immersion. For both antibiofilm activity and physical/mechanical analysis, the specimens were randomly assigned to four groups according to the following hygiene solutions: I) Distilled water (Control); II) $0.2 \%$ Sodium Hypochlorite [SH - (Inject Center Manipulation Pharmacy, Ribeirão Preto, São Paulo, Brazil)]; III) Efferdent Power Clean Crystals (EPC - Medtech Products, Irvington, New York, USA); IV) $6.25 \%$ Ricinus communis (RC - Institute of Cheminstry of São Carlos, São Carlos, São Paulo, Brazil). The active substances of the Efferdent Power Clean Crystals are sodium perborate and ethylenediaminetetraacetic acid (EDTA) tetrasodium, which are responsible for the release of active oxygen, promoting antimicrobial and stain removal effect. ${ }^{22}$ In Groups Control, $\mathrm{SH}$ and $\mathrm{RC}$, immersions were performed at room temperature, whereas in Group EPC, immersions were performed in accordance with the manufacturer's instructions (3 $\min / 37 \pm 2^{\circ} \mathrm{C}$ ). In the 5 -year immersion simulation performed for physical/mechanical analysis, one hour was considered to represent 3 immersions of $20 \mathrm{~min}$, thus every $24 \mathrm{~h}$ corresponded to 72 immersions. Therefore, to complete the period (1825 days), 25.3 days were necessary. ${ }^{17}$ Considering 3-minute immersion, one hour represented 480 immersions, thus 3.8 days were required to complete the period. The specimens were evaluated before and after this immersion protocol.

\section{Specimen preparation}

Circular $(15 \times 3 \mathrm{~mm})$, rectangular $(65 \times 10 \times 3.3 \mathrm{~mm})$ and disc-shaped $(50 \times 0.5 \mathrm{~mm})$ metal matrices were invested with type IV dental stone (Gesso Rio, Rio Claro, São Paulo, Brazil) in a conventional denture flask. Afterwards, heat-polymerized acrylic resin (Classico, Campo Limpo Paulista, São Paulo, Brazil) was manipulated, packed, and pressed into the mold and polymerized by immersion in water $\left(73^{\circ} \mathrm{C}\right.$ for $90 \mathrm{~min}$ and boiling for $30 \mathrm{~min}$ ), in an electric thermopolymerizing device (Thermocycler T100; University of São Paulo, Ribeirão Preto, São Paulo, Brazil). The specimens were deflasked and immersed in distilled water at $50^{\circ} \mathrm{C}$ for $24 \mathrm{~h}$ in order to eliminate residual monomer. Excess acrylic resin was removed with a bur (Maxi-Cut; Malleifer Instruments, Ballaiguer, Switzerland) and a micromotor (Moto Torre; EDG, São Carlos, São Paulo, Brazil). All specimen surfaces were polished in a horizontal polisher (Aropol E; Arotec, Cotia, São Paulo, Brazil) with abrasive paper (Norton Indústria Brasileira, Guarulhos, São Paulo, Brazil).

\section{Antibiofilm Activity}

Antibiofilm activity was evaluated in triplicate, in three independent time intervals $(n=9)$, against three strains from the American Type Culture Collection (ATCC): Candida albicans (10231), Candida glabrata, (2001) and Streptococcus mutans (25175). Firstly, stock cultures of frozen yeasts and bacteria were streaked out on Sabouraud Dextrose Agar (Himedia, Mumbai, India) plates and Brain Heart Infusion Agar (Himedia) plates, respectively. After incubation at $37^{\circ} \mathrm{C}$ for $48 \mathrm{~h}$ one colony was transferred to $10 \mathrm{ml}$ of broth medium and incubated at $37^{\circ} \mathrm{C}$ to obtain exponentially growing cells. Afterwards, the tubes were centrifuged (Eppendorf, Hamburg, Germany) and the cell pellet was washed twice in phosphate-buffered saline (PBS). Optical density of $S$. mutans suspensions was verified in a spectrophotometer (Multiskan GO; Thermo Scientific, Waltham, Massachusetts, USA) at wavelength of $625 \mathrm{~nm}$. Due to the variable morphology of the genus, yeast cell density was verified using a Neubauer chamber (Precicolor; HBG HennebergSander, Gießen, Germany).

Monospecies biofilms were grown according to Paranhos, et al. ${ }^{29}$ (2019). Briefly, the circular specimens, sterilized by microwave irradiation [127 V, 800 W, 2,450 MHz (Perfect; Panasonic, Kadoma, Japan), at $650 \mathrm{~W}$ for 6 minutes, were aseptically distributed into 12-well tissue culture plates (TPP Techno Plastic Products, Trasadingen, Switzerland). Each well received $2 \mathrm{ml}$ of medium broth containing standardized cell suspension $\left(10^{6} \mathrm{CFU} / \mathrm{ml}\right)$ of $C$. albicans, C. glabrata or S. mutans. The plates were incubated at $37^{\circ} \mathrm{C}$, at $75 \mathrm{rpm}$ for $48 \mathrm{~h}$ to promote biofilm maturation. After incubation, the specimens 
were randomly assigned, and the proposed hygiene protocols were applied concurrently on three specimens with the monospecies biofilm. Specimens was transferred to a stainless-steel basket $(6 \mathrm{~cm} \times 3$ $\mathrm{cm} \times 2 \mathrm{~cm})$ with 6 square compartments $(1.5 \mathrm{~cm} \times 1.5$ $\mathrm{cm}$ ) and immersed in a container with $200 \mathrm{ml}$ of the respective cleansing solutions. ${ }^{23}$ For Group EPC, one sachet of powder was added to the sterile distilled water $\left(37 \pm 2^{\circ} \mathrm{C}\right)$. After immersion, specimens were washed with PBS, transferred to $10 \mathrm{ml}$ of Letheen broth (HiMedia) and sonicated (200W, 40KHz) (Altsonic Clean; Alt equipamentos, Ribeirão Preto, São Paulo, Brazil) for $20 \mathrm{~min}$. Serial dilutions aliquots $\left(10^{1}-10^{3}\right)$ of the resulting suspension were seeded, the number of colonies was registered, and the $\mathrm{CFU} / \mathrm{ml}$ value was calculated.

After hygiene procedure, two specimens of each group were fixed with $2.5 \%$ glutaraldehyde for $60 \mathrm{~min}$ and subsequently dehydrated in a graded ethanol series (30\%, 50\%, 70\%, 90\% and 100\%). The specimens were sputter-coated with a layer of approximately $100 \mathrm{~nm}$ gold and positioned in a Scanning Electron Microscope (EVO 10; CARL ZEISS, Jena, Germany). Surface morphology of the biofilms was examined at $3000 \times$ magnifications under high vacuum.

\section{Effect on physical and mechanical properties of acrylic resin \\ Surface roughness}

The roughness of rectangular specimens was evaluated with a rugosimeter (Surftest SJ-201P; Mitutoyo, Tokyo, Japan) $(n=20)$ and a 3D laser confocal microscope (OLS4000; Olympus Tokyo, Japan) $(n=3)$. Using the rugosimeter, three readings were performed ( $4 \mathrm{~mm}$ in length) for each specimen, and the cut-off value was $0.8 \mathrm{~mm}$ at a speed of $0.5 \mathrm{~mm} / \mathrm{s}$. The roughness of each specimen was calculated by the arithmetic mean of three measurements $(\mu \mathrm{m})$. Values within $0.20 \mu \mathrm{m}$ were considered clinically acceptable. ${ }^{17,21}$ For analysis under the 3D laser confocal microscope, the specimens were placed in a parallel position and 3 random images were captured. The images were obtained with a $5 \times$ objective, at a final magnification of $108 \times$, and the mean roughness of each image (Sa) was calculated.

\section{Color Change}

The color measurements $(n=20)$ were made on circular specimens by using a colorimeter (Color- guide 45/0; BYK-Gardner, Geretsried, Germany) as previously described. ${ }^{17}$ The CIELAB color scale was used to calculate change in color of each specimen using the $\Delta \mathrm{E}$ equation $\left\{\Delta \mathrm{E}^{*}=\left[\left(\Delta \mathrm{L}^{*}\right)^{2}+\left(\Delta \mathrm{a}^{*}\right)^{2}+\left(\Delta \mathrm{b}^{*}\right)^{2}\right]^{1 / 2}\right\}$. The data were also quantified according to the National Bureau of Standards (NBS) units (NBS units $=\Delta E \times$ 0.92 ) and changes were then classified according to: 1) Trace, $0.0-0.5$; 2) Slight, 0.5-1.5; 3) Noticeable, 1.5-3.0; 4) Considerable, 3.0-6.0; 5) Very, 6.0-12.0; 6) Excessive, $>12.0$.

\section{Microhardness}

The surface microhardness was analyzed on circular specimens $(n=20)$ according to specification ISO 4516:2002, using a microdurometer (HMV-2000; Shimadzu, Kyoto, Japan). ${ }^{15}$ Eight random equidistant measurements (40x magnification) were made on each specimen with a Knoop diamond indenter under a load of $25 \mathrm{~g}$ for 5 seconds. The microhardness of each specimen was defined by the mean of the eight measurement values obtained.

\section{Flexural strength}

The flexural strength of rectangular specimens $(n=20)$ was determined by applying the 3-point bending test according to specification ISO 20795$1: 2008$, using a universal testing machine (DL 2000; EMIC, São Jose dos Pinhais, Paraná, Brazil). With $50 \mathrm{~mm}$ of distance between the two supporting points, $50 \mathrm{~kg}$ were applied on the center of specimens until they fractured. ${ }^{21}$ Flexural strength was calculated using the peak load applied, span length and specimen widths and thicknesses. The results were expressed in $\mathrm{kgf} / \mathrm{mm}^{2}$ and converted to MPa. Flexural strength values below $65 \mathrm{MPa}$ were not considered clinically acceptable, in accordance with the ADA Specification No. $12 .{ }^{14}$

\section{Impact strength}

Rectangular specimens $(n=20)$ were submitted to the Izod type impact test without notch (AIC; EMIC, São José dos Pinhais, Paraná, Brazil), in accordance with specification ASTM D256. ${ }^{37}$ Specimens were placed on the testing machine in a vertical position, so that the 2J-pendulum reached their upper free end. The results were expressed in $\mathrm{J} / \mathrm{m}$.

\section{Sorption and solubility}

Sorption and solubility tests were conducted on disc-shaped specimens $(n=20)$ in accordance with specification ANSI/ADA No.12/1975. ${ }^{38}$ Sorption was determined according to increase in mass per unit 
volume, while solubility was determined according to loose of mass from specimens. The specimens were weighed (AB204; Metler Toledo, Columbus, Ohio, USA) and placed in desiccators until constant mass was reached (M1). Subsequently, the specimens were immersed in the hygiene solutions and weighed again (M2). After immersions, the specimens were placed in desiccators again, to obtain the constant mass (M3). The sorption and solubility calculations were based on the equations (M2-M1)/V and (M1-M3)/V, respectively; (in which: $V=$ the specimen volume) and expressed in $\mathrm{g} / \mathrm{cm}^{3}$.

\section{Data analysis}

All statistical comparisons were made by IBM SPSS statistics software (SPSS Statistics for Windows, Version 21.0. Armonk, NY, USA). The datasets of results were evaluated for normality of distribution (Shapiro-Wilk test). Data for $S$. mutans antibiofilm activity, surface roughness, color alteration, microhardness, flexural and impact strength, sorption, and solubility showed a non-normal distribution, thus the Kruskal-Wallis test and Dunn posttest were performed $(a=0.05)$. For $C$. albicans and C. glabrata antibiofilm activity and surface roughness under 3D laser confocal microscope, the ANOVA and Tukey post tests $(\alpha=0.05)$ were used. All multiple comparisons were performed with Bonferron adjustment.

\section{Results}

\section{Antibiofilm activity}

Antibiofilm activity was solution dependent. $\mathrm{SH}$ reduced the counts of $C$. albicans, $C$. glabrata and S. mutans biofilms on acrylic resin surfaces to zero. Compared with the control group, immersion in EPC exhibited an evident reduction in $S$. mutans biofilm $(p=0.001)$ and immersion in RC promoted favorable antibiofilm activity against $C$. glabrata $(p<0.001)$. Table 1 exhibits $\log _{10}{ }^{(C F U+1)}$ for the different microorganisms. Figure 1 shows representative scanning electron microscopy images after immersion in the hygiene solutions. The images illustrate a substantial reduction of C. albicans, C. glabrata and S. mutans biofilm after immersion in $\mathrm{SH}$.

\section{Surface roughness}

Surface roughness was also solution dependent. After immersion in RC a significant increase in surface roughness was observed $(p<0.05)$. Higher surface roughness values were identified for both evaluation methods, i.e., by rugosimeter $(\Delta \mathrm{Ra})$ and under $3 \mathrm{D}$ laser confocal microscope (Sa). The method of 3D laser confocal microscope seemed to be more sensitive for evaluating the surface roughness. $\Delta \mathrm{Ra}(\mu \mathrm{m})$ and $\mathrm{Sa}$ $(\mu \mathrm{m})$ values are shown in Table 2 . Three-dimensional laser confocal microscopy images are presented in Figure 2. Although a significant alteration could be identified after data analysis ( $\triangle \mathrm{Ra}$ and $\mathrm{Sa}$ ), the roughness surface did not vastly change among the groups $(0.00-0.03 \mu \mathrm{m})$.

Table 1- Log10(CFU+1) of C. albicans, C. glabrata and S. mutans biofilms after immersion in different hygiene solutions

\begin{tabular}{|c|c|c|c|c|c|c|}
\hline Microorganisms & Hygiene Solutions & $\begin{array}{c}\text { Mean } \pm \text { SD } \\
\text { (Median) }\end{array}$ & 95\% IC (Range) & p & $\begin{array}{c}\text { Pairwise } \\
\text { Comparisions }\end{array}$ & \\
\hline \multirow{4}{*}{ C. albicans } & Control & $4.93 \pm 0.29(4.89)$ & $4.70 ; 5.15(4.54 ; 5.47)$ & \multirow{4}{*}{$0.212^{*}$} & & \\
\hline & $\mathrm{RC}$ & $4.53 \pm 0.57(4.31)$ & $4.09 ; 4.97(3.70 ; 5.58)$ & & & \\
\hline & $\mathrm{SH}^{+}$ & $0.00 \pm-(0.00)$ & $-;-(0.00 ; 0.00)$ & & & \\
\hline & EPC & $4.66 \pm 0.51(4.59)$ & $4.27 ; 5.05(3.93 ; 5.45)$ & & & \\
\hline \multirow{4}{*}{ C. glabrata } & Control & $5.98 \pm 0.28(6.04)$ & $5.77 ; 6.19(5.45 ; 6.31)$ & \multirow{4}{*}{$<0.001^{*}$} & \multirow{2}{*}{$<0.001$} & \\
\hline & $\mathrm{RC}$ & $5.38 \pm 0.32(5.41)$ & $5.13 ; 5.63(4.82 ; 5.80)$ & & & \\
\hline & $\mathrm{SH}^{+}$ & $0.00 \pm-(0.00)$ & $-;-(0.00 ; 0.00)$ & & - & \\
\hline & EPC & $5.93 \pm 0.20(5.93)$ & $5.78 ; 6.08(5.71 ; 6.26)$ & & \rfloor 0.001 & \\
\hline \multirow{4}{*}{ S. mutans } & Control & $6.90 \pm 0.37(7.08)$ & $6.61 ; 7.18(6.06 ; 7.26)$ & \multirow{4}{*}{$<0.001^{* *}$} & \multirow{4}{*}{$<0.001$} & \\
\hline & $\mathrm{RC}$ & $6.93 \pm 0.34(7.02)$ & $6.67 ; 7.19(6.36 ; 7.32)$ & & & \multirow{3}{*}{$<0.001$} \\
\hline & $\mathrm{SH}^{+}$ & $0.00 \pm-(0.00)$ & $-;-(0.00 ; 0.00)$ & & & \\
\hline & EPC & $4.71 \pm 0.85(4.79)$ & $4.06 ; 5.36(3.56 ; 6.01)$ & & & \\
\hline
\end{tabular}

'without CFU values after immersion, *ANOVA and Tukey pos-test; **Kruskal-Wallis test and Dunn pos-test. RC - Ricinus communis; SH - Sodium Hypochorite; EPC - Efferdent Power Clean. 


\section{Color Change}

According to the CIELAB color scale $(\Delta E)$, change in color was observed after immersion in all hygiene solutions. Significantly higher $\Delta \mathrm{E}$ values were observed only for Group RC when compared with Control $(p=0.030), \mathrm{SH}(p<0.001)$ and EPC $(p=0.011)$. Nonetheless, when classifying the change in color according to the NBS units the values were less divergent ["trace" (0.0-0.5) for SH (0.43) and "slight" (0.5-1.5) for Control (0.78), EPC (0.89) and RC (1.27)]. Table 2 shows the color change results.

\section{Microhardness}

The Kruskal-Wallis test showed a significant difference for microhardness $(p<0.001)$. The Dunn test indicated that immersion in RC increased microhardness values, which differed statistically from those of Control $(p<0.001)$, SH $(p<0.001)$ and EPC $(p=0.001)$ (Table 2).

\section{Flexural strength}

Relative to flexural strength, significantly lower values were observed after immersion in RC when compared with control $(p=0.006), \mathrm{SH}(p=0.025)$ and without immersion $(p<0.001)$. Whereas higher values
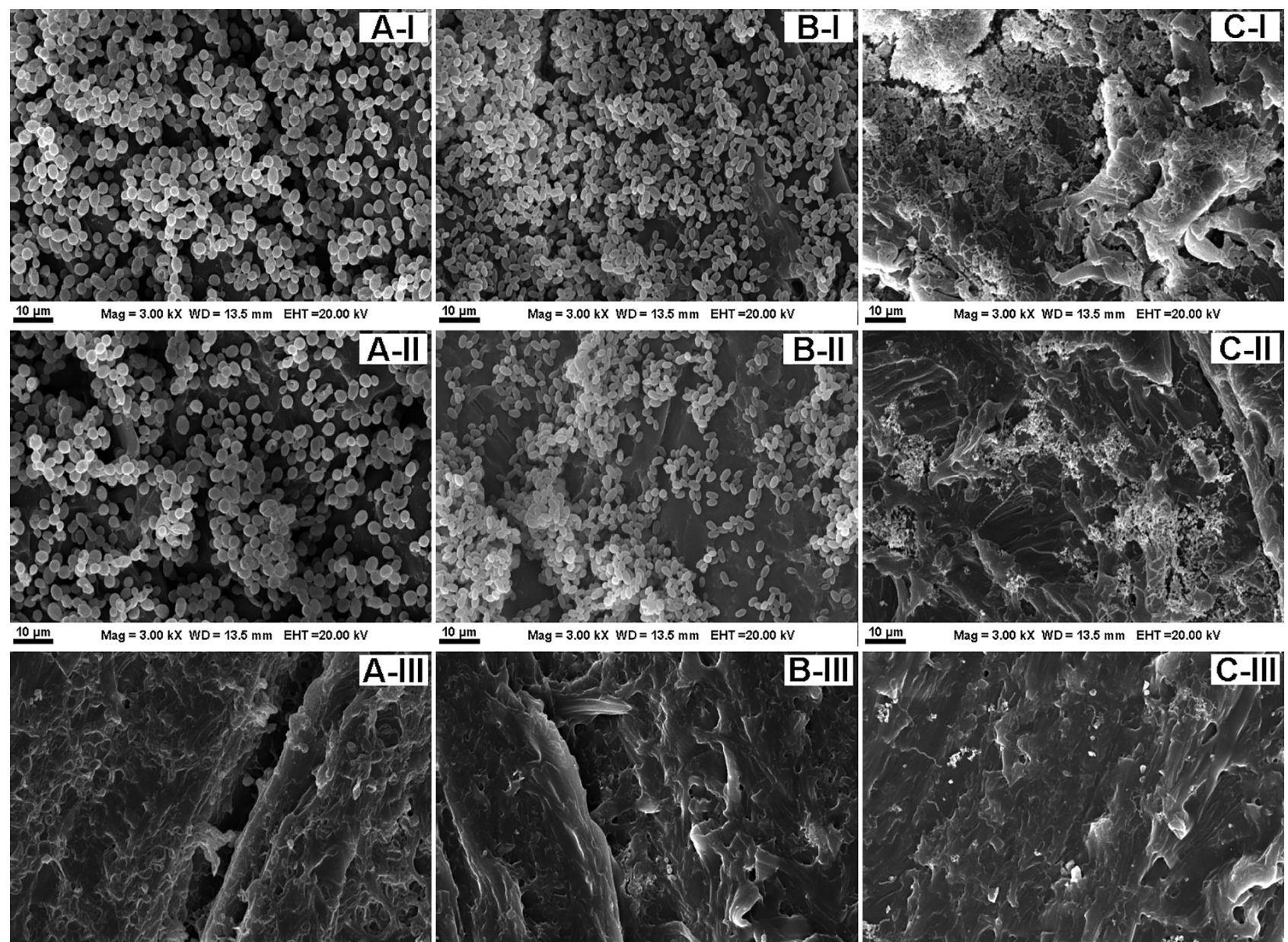

$10 \mathrm{~mm}$

$\mathrm{Mag}=3.00 \mathrm{kX}$ WD $=13.5 \mathrm{~mm} \quad \mathrm{EHT}=20.00 \mathrm{kV}$
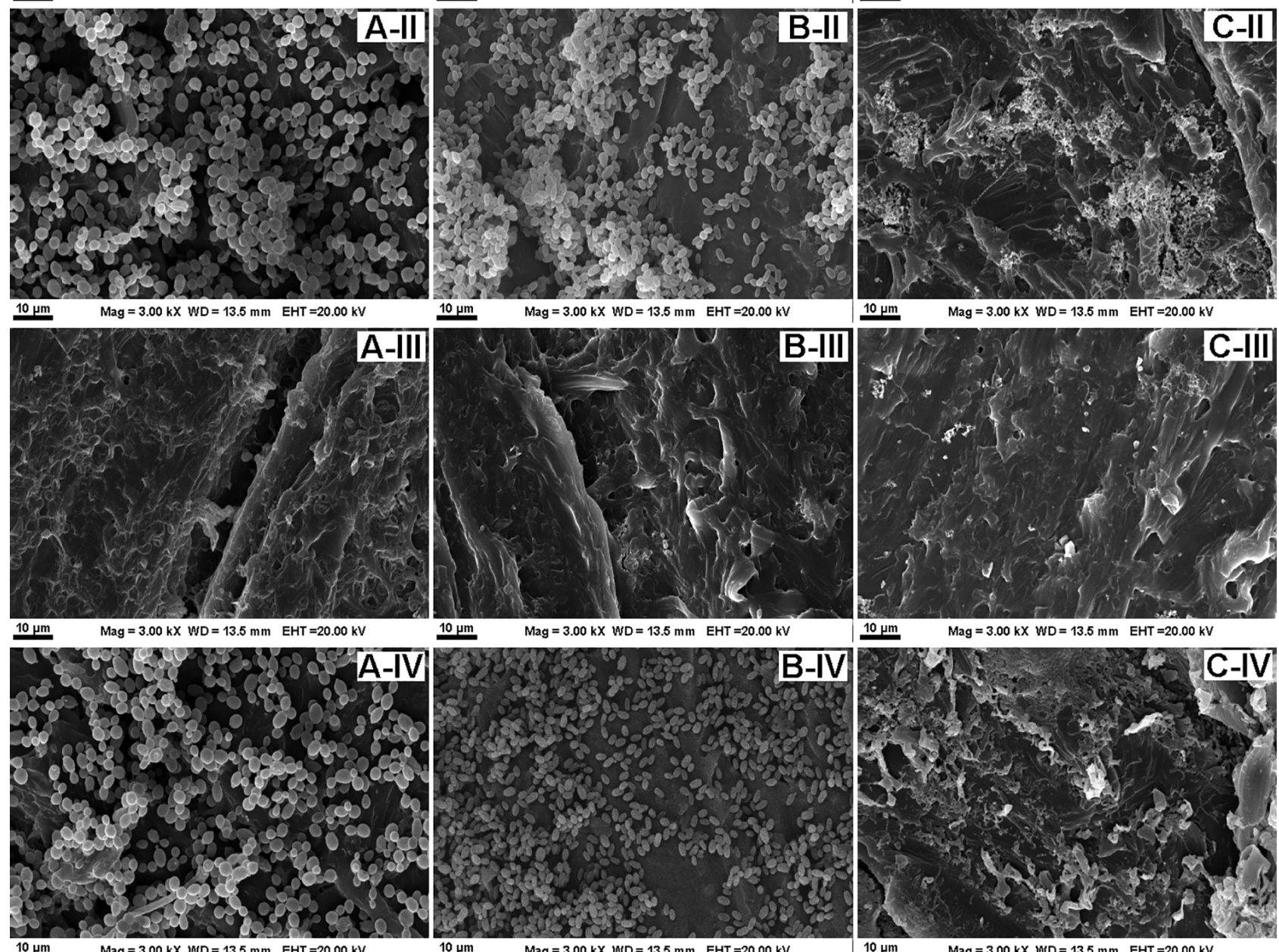

$10 \mu \mathrm{m}$

$\mathrm{Mag}=3.00 \mathrm{kX} W \mathrm{WD}=13.5 \mathrm{~mm} \quad \mathrm{EHT}=20.00 \mathrm{kV}$

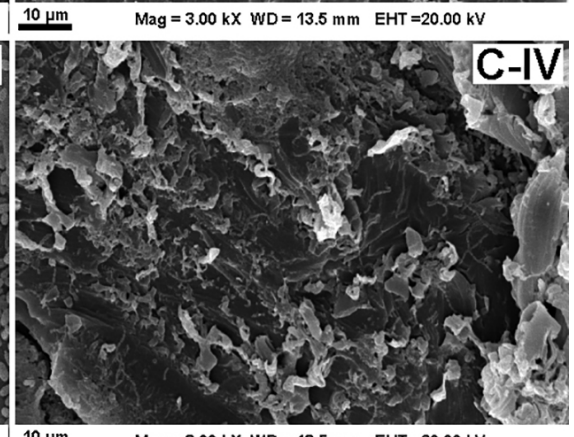

Figure 1- Representative scanning electron microscopy images after immersion in different hygiene solutions. A) C. albicans; B) C. glabrata; C) S. mutans. I) Control; II) RC - R. communis; III) SH - Sodium Hypochlorite; IV) EPC - Efferdent Power Clean. Magnification $3000 \times$. Scale bar $=10 \mu \mathrm{m}$ 
Table 2- Effects of different hygiene solutions on physical and mechanical properties of denture base acrylic

\begin{tabular}{|c|c|c|c|c|c|c|}
\hline $\begin{array}{c}\text { Physical and } \\
\text { Mechanical Properties }\end{array}$ & $\begin{array}{l}\text { Hygiene } \\
\text { Solutions }\end{array}$ & Mean \pm SD (Median) & $95 \%$ IC (Range) & $\mathbf{p}$ & $\begin{array}{l}\text { Pai } \\
\text { Comp }\end{array}$ & $\begin{array}{l}\text { ise } \\
\text { isions }\end{array}$ \\
\hline \multirow{4}{*}{$\begin{array}{l}\text { Surface roughness - } \\
\qquad \Delta \mathrm{Ra}(\mu \mathrm{m})\end{array}$} & Control & $0.00 \pm 0.03(0.00)$ & $-0.02 ; 0.01(-0.10 ; 0.02)$ & \multirow{4}{*}{$0.003^{* *}$} & \multirow{2}{*}{0.006} & \\
\hline & $\mathrm{RC}$ & $0.03 \pm 0.04(0.02)$ & $0.01 ; 0.06(-0.01 ; 0.16)$ & & & \\
\hline & $\mathrm{SH}$ & $0.02 \pm 0.03(0.01)$ & $0.01 ; 0.03(-0.01 ; 0.08)$ & & \multirow[t]{2}{*}{0.027} & \\
\hline & EPC & $0.01 \pm 0.02(0.00)$ & $0.00 ; 0.02(-0.02 ; 0.07)$ & & & \\
\hline \multirow{5}{*}{ Surface roughness - Sa $(\mu \mathrm{m})$} & WI & $0.327 \pm 0.065(0.340)$ & $0.277 ; 0.376(0.213 ; 0.432)$ & \multirow{5}{*}{$0.001^{*} \neg$} & \multirow{5}{*}{$\begin{array}{l}<0.001 \\
0.006\end{array}$} & \multirow{5}{*}{0.040} \\
\hline & Control & $0.282 \pm 0.045(0.269)$ & $0.248 ; 0.317(0.229 ; 0.348)$ & & & \\
\hline & $\mathrm{RC}$ & $0.410 \pm 0.074(0.401)$ & $0.353 ; 0.467(0.329 ; 0.540)$ & & & \\
\hline & $\mathrm{SH}$ & $0.306 \pm 0.032(0.306)$ & $0.281 ; 0.331(0.253 ; 0.352)$ & & & \\
\hline & EPC & $0.339 \pm 0.073(0.351)$ & $0.283 ; 0.395(0.262 ; 0.498)$ & & & \\
\hline \multirow{4}{*}{ Color $(\Delta \mathrm{E})$} & Control & $0.85 \pm 0.66(0.66)$ & $0.54 ; 1.16(0.34 ; 2.90)$ & \multirow{4}{*}{$<0.001^{* *}$} & \multirow{4}{*}{$\begin{array}{r}0.030 \\
<0.001\end{array}$} & \multirow{4}{*}{0.011} \\
\hline & $\mathrm{RC}$ & $1.37 \pm 0.84(1.07)$ & $0.98 ; 1.76(0.22 ; 3.94)$ & & & \\
\hline & $\mathrm{SH}$ & $0.52 \pm 0.21(0.41)$ & $0.42 ; 0.61(0.32 ; 0.94)$ & & & \\
\hline & EPC & $0.97 \pm 1.03(0.61)$ & $0.48 ; 1.45(0.19 ; 4.54)$ & & & \\
\hline \multirow{4}{*}{ Microhardness $(\Delta \mathrm{HK})$} & Control & $-0.28 \pm 1.69(-0.05)$ & $-1.07 ; 0.52(-5.10 ; 2.10)$ & \multirow{4}{*}{$0.001^{\star *}$} & \multirow{4}{*}{$\begin{array}{l}<0.001 \\
<0.001\end{array}$} & \multirow{4}{*}{0.001} \\
\hline & $\mathrm{RC}$ & $2.91 \pm 1.82(2.85)$ & $2.06 ; 3.76(-0.10 ; 6.60)$ & & & \\
\hline & $\mathrm{SH}$ & $0.16 \pm 0.82(0.05)$ & $-0.23 ; 0.54(-1.20 ; 1.60)$ & & & \\
\hline & EPC & $0.54 \pm 1.58(0.25)$ & $-0.20 ; 1.28(-1.50 ; 4.30)$ & & & \\
\hline \multirow{5}{*}{ Flexural Strength (MPa) } & WI & $96.15 \pm 8.53(98.92)$ & $92.16 ; 100.14$ (78.94; 106.84) & \multirow{5}{*}{$<0.001^{* *}$} & \multirow{5}{*}{$<0.001$} & \multirow{5}{*}{$\begin{array}{l}0.006 \\
<0.001\end{array}$} \\
\hline & Control & $89.94 \pm 7.58(90.08)$ & $86.39 ; 93.49$ (72.52; 103.75) & & & \\
\hline & $\mathrm{RC}$ & $74.18 \pm 10.25(74.39)$ & $69.39 ; 78.98$ (56.21; 101.95) & & & \\
\hline & $\mathrm{SH}$ & $88.21 \pm 10.16(86.50)$ & $83.45 ; 92.97$ (67.79; 104.95) & & & \\
\hline & EPC & $99.73 \pm 9.12(100.94)$ & $95.46 ; 103.99(72.17 ; 114.58)$ & & & \\
\hline \multirow{5}{*}{ Impact Strength $(\mathrm{J} / \mathrm{m})$} & WI & $165.10 \pm 7.59(164.00)$ & $161.55 ; 168.65(156.00 ; 183.00)$ & \multirow{5}{*}{$<0.001^{* *}$} & & \multirow{5}{*}{0.00} \\
\hline & Control & $146.40 \pm 12.56(147.50)$ & $140.52 ; 152.28(128.00 ; 163.00)$ & & & \\
\hline & $\mathrm{RC}$ & $132.40 \pm 11.68(135.00)$ & $126.93 ; 137.87(110.00 ; 150.00)$ & & & \\
\hline & $\mathrm{SH}$ & $141.15 \pm 7.10(144.00)$ & $137.83 ; 144.47(128.00 ; 153.00)$ & & & \\
\hline & EPC & $134.10 \pm 10.50(140.00)$ & $129.18 ; 139.02(113.00 ; 144.00)$ & & & \\
\hline \multirow{4}{*}{ Sorption $\left(\mathrm{g} / \mathrm{cm}^{3}\right)$} & Control & $0.027 \pm 0.002(0.028)$ & $0.026 ; 0.028(0.022 ; 0.031)$ & \multirow{4}{*}{$0.666^{\star *}$} & & \\
\hline & $\mathrm{RC}$ & $0.026 \pm 0.073(0.028)$ & $-0.008 ; 0.060(-0.201 ; 0.169)$ & & & \\
\hline & $\mathrm{SH}$ & $0.027 \pm 0.003(0.028)$ & $0.025 ; 0.029(0.019 ; 0.033)$ & & & \\
\hline & EPC & $0.028 \pm 0.002(0.028)$ & $0.027 ; 0.029(0.024 ; 0.033)$ & & & \\
\hline \multirow{4}{*}{ Solubility $\left(\mathrm{g} / \mathrm{cm}^{3}\right)$} & Control & $-0.005 \pm 0.016(-0.001)$ & $-0.012 ; 0.003(-0.073 ;-0.001)$ & \multirow{4}{*}{$<0.001^{* *}$} & & \\
\hline & $\mathrm{RC}$ & $-0.002 \pm 0.072(-0.002)$ & $-0.036 ; 0.032(-0.147 ; 0.219)$ & & & \\
\hline & $\mathrm{SH}$ & $0.002 \pm 0.016(-0.001)$ & $-0.005 ; 0.010(-0.002 ; 0.070)$ & & $<0.001$ & \\
\hline & EPC & $-0.001 \pm 0.000(-0.001)$ & $-0.001 ;-0.001(-0.001 ; 0.000)$ & & & \\
\hline
\end{tabular}

*ANOVA and Tukey pos-test; **Kruskal-Wallis test and Dunn pos-test. RC - Ricinus communis; SH - Sodium Hypochorite; EPC - Efferdent Power Clean.

were observed after immersion in EPC when compared with $\mathrm{RC}(p<0.001)$ and $\mathrm{SH}(p=0.014)$. Flexural strength results are illustrated in Table 2.

\section{Impact strength}

A reduction in impact strength was observed after immersion in all hygiene solutions. The group without immersion exhibited the highest impact strength values that differed statistically from those of Control $(p=0.003), \mathrm{SH}(p<0.001), \mathrm{RC}(p<0.001)$ and EPC $(p<0.001)$ (Table 2).

\section{Sorption and solubility}

For sorption, no changes were observed after immersion in all hygiene solutions $(p=0.666)$ (Table 2$)$. However, for solubility, immersion in RC contributed to greater weight loss than immersion in EPC $(p<0.001)$ (Table 2).

\section{Discussion}

In this study, hygiene solutions were evaluated 


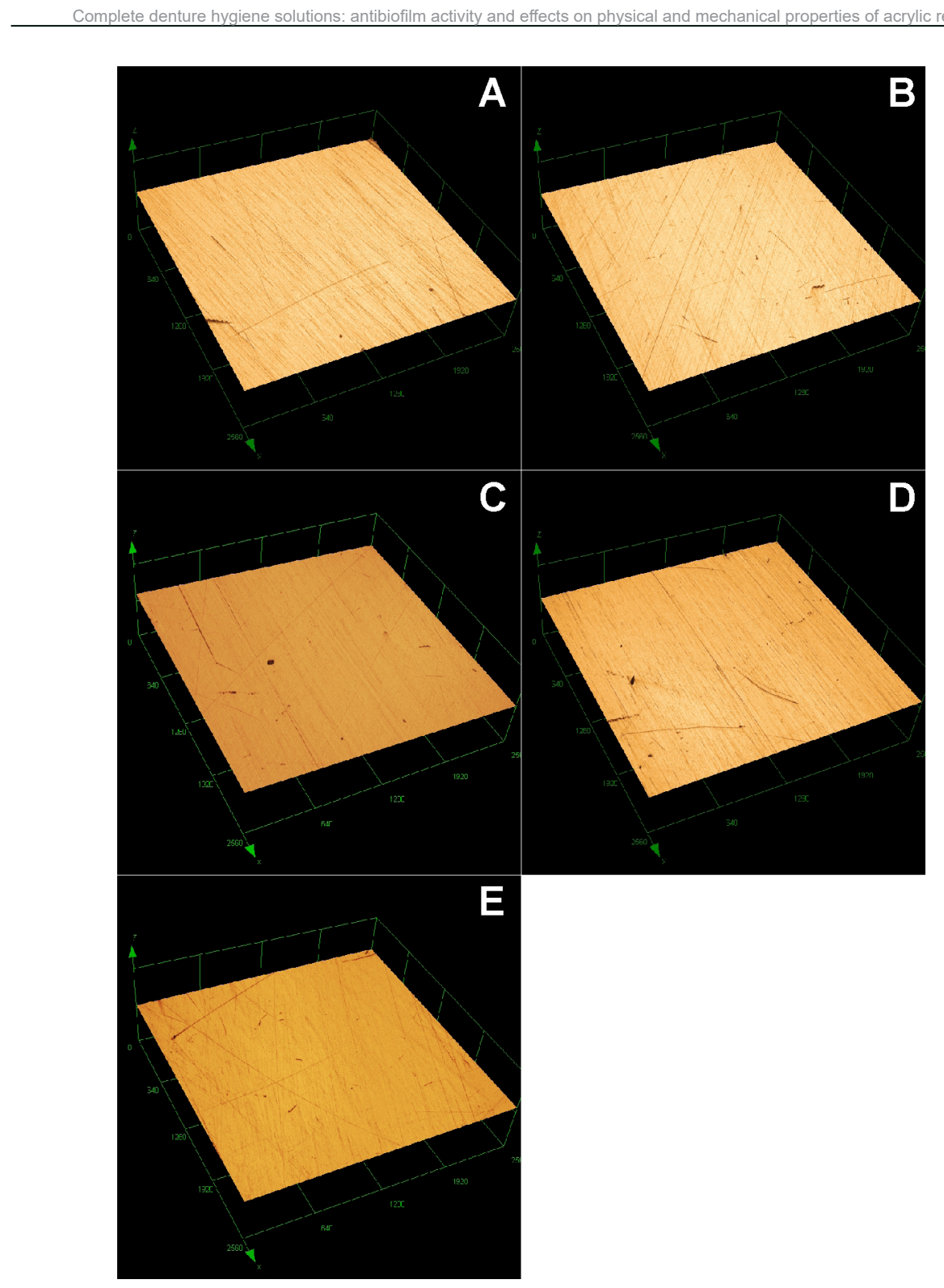

Figure 2- Representative 3D laser confocal microscopy images of specimens after immersion in different hygiene solutions. A) WI Without Immersion; B) Control; C) RC - R. communis; D) SH - Sodium Hypochlorite; E) EPC - Efferdent Power Clean. Magnification 108×

with regard to antibiofilm activity against $C$. albicans, C. glabrata and S. mutans that are microorganisms related to denture biofilm, ${ }^{1}$ and adverse effects on relevant properties of the acrylic resin-based dentures. ${ }^{15-17,19}$ The solutions were applied in short cycles (20 minutes), as a routinely recommended period of immersion, and were not associated with any other hygiene methods, to avoid the synergism of action. ${ }^{3,23}$ The results demonstrated rejection of the null hypothesis, since the solutions showed different effects on antibiofilm activity, surface roughness, color change, microhardness, flexural and impact strength and solubility.

As regards antibiofilm activity, $\mathrm{SH}$ was the most effective solution since it reduced the CFU counts of the three microorganisms to zero. Studies have shown the efficacy of $\mathrm{SH}$ in removing denture biofilm, ${ }^{7-10,28}$ even in diluted concentrations of $0.1 \%$ and $0.2 \% .^{20-}$ 22 Concentrations at $0.5 \%$ and $0.25 \%$ showed antimicrobial effectiveness against yeast and bacteria (Gram positive and negative), $4-6,8-11$ and at $0.1 \%$ and $0.2 \%$, against Candida spp. ${ }^{20-22}$ Moreover, the literature has shown that elevated concentrations, i.e. $1 \%$, should not be used, since these concentrations led to changes in color and flexural strength of the acrylic resins. ${ }^{13,15}$ Concentrations of $0.5 \%$ were not deleterious in short cycles (3-20 minutes), or in periods ranging from 180 days $^{8,12,18}$ to 5 years ${ }^{17}$ of daily use. However, this concentration led to changes in color and surface roughness when applied in long cycles ( 8 hours). ${ }^{13,16}$ A previous study showed that a $0.2 \% \mathrm{SH}$ solution promoted color change classified as "trace" according to NBS, without changes in the surface roughness and flexural strength of the acrylic resin. ${ }^{21}$ The results 
of the present study complement these findings, since we observed no changes in microhardness, sorption, solubility and surface morphology. Thre were changes only in impact strength, but within the values established by ISO 1567. 15,37 Thus, it can be inferred that this solution is effective and can be indicated as a safe denture cleanser in short immersions.

EPC was effective against $S$. mutans, in agreement with a previous study, ${ }^{29}$ but ineffective against $C$. albicans and C. glabrata. Peroxide-based solutions, in general, have shown a wide variety of results regarding biofilm removal and antimicrobial action against different microorganisms, with reports of effectiveness, ${ }^{3,23,30-33}$ moderate action ${ }^{27,29}$ and ineffectiveness. ${ }^{9,25}$ These findings may be related to the different methodologies used, such as hygiene protocol used, microorganisms, biofilm recovery rates, biofilm composition ${ }^{23,26,29}$ and even the cleanser itself, since the effectiveness of peroxides is regularly attributed to the active ingredients of the formulations. $24,27,29$ The effectiveness of Efferdent has been associated with the presence of tetrasodium EDTA in its composition. ${ }^{27}$ Its action against $S$. mutans, microorganisms related to the growth of Candida in biofilms, was a relevant result and emphasized the importance of using this solution as a denture cleanser. Other protocols of use should be evaluated, since the product has been indicated for longer periods of immersion, with the aim of increasing its effectiveness. ${ }^{19,31}$ With reference to the effects on acrylic resin, similarly to the trend in results observed for $\mathrm{SH}$, there was only a decrease in impact strength. Previous studies have shown that different peroxide-based solutions have decreased the flexural strength of acrylic resins, and promoted color changes classified as "noticeable", "considerable" and "very". ${ }^{14,16,34}$ Therefore, these findings may be related to the different compositions of the cleansers. Regarding surface morphology, after immersion in EPC, the acrylic resin acquired a rougher exterior surface. The exact mechanism that alkaline peroxides damage the acrylic resin surface is unclear. It has been proposed that the higher peroxide content and release of oxygen can promote hydrolysis and surface decomposition. ${ }^{39}$

RC showed antibiofilm activity against C. glabrata, with a significant decrease in microbial load; however, in agreement with Badaró, et al. ${ }^{10}$ (2017), it was not effective against $C$. albicans and $S$. mutans. Randomized clinical studies have demonstrated moderate efficacy in biofilm removal of RC at $2 \%, 8 \%$ and $10 \%, 7,10,21,35$ effectiveness of remission of denture stomatitis at $3.3 \%, 8 \%$ and $10 \% 10,20,36$ and antimicrobial action at $2 \%$ and $10 \%{ }^{6,10}$ However, Candida spp. have been shown to be more resistant to these solutions, with reports of moderate action of solutions at 2 and $10 \%{ }^{6}$ and ineffectiveness of solutions at $3.3 \%$ and $8 \% .20,36$ These results differed from the findings of this study, since the concentration of $6.25 \%$ was effective against C. glabrata. Thus, the concentration of RC seems to be a determining factor for effectiveness, so that the ideal amount of water is essential to allow the breakdown of sugar molecules in the cell walls and inactivation of ribosome that promotes cell death. ${ }^{20,22}$ Regarding the adverse effects, in addition to the decrease in impact strength, the solution also led to greater changes in color, microhardness, flexural strength and surface roughness; however, the values were within acceptable clinical limits for each property. ${ }^{15,17}$ Even though the sorption was similar among the groups, RC showed the highest range of values. According to Tuna, et al. ${ }^{40}$ (2008) water and chemicals absorbed from the environment, would cause the decrease of mechanical properties. So, this statement indicates that RC could had bound chemically to acrylic resin, influencing the evaluated properties.

Furthermore, when compared with EPC, the RC solution promoted moderate changes in surface morphology and lower values of mass loss. The few reports in the literature showed that irrespective of the concentration used, RC promoted color changes, however, within the clinical limits established according to the National Bureau of Standards (NBS). ${ }^{15,18,21}$ Changes in surface roughness have also been reported with concentrations at $2 \%$ and $10 \%$, as well as decrease in microhardness and flexural strength at $2 \%$ concentration. ${ }^{15,18}$ However, when conducted at $8 \%$, no change in the properties of surface roughness and flexural strength was identified. ${ }^{21}$ Therefore, obtaining an ideal concentration of RC is important, not only to guarantee its effectiveness against the denture biofilm, but also to prevent changes in the properties of the acrylic resin-based dentures. According to results obtained, RC can be indicated as a denture cleanser, since it demonstrated antibiofilm action against $C$. glabrata, without showing significant changes in the properties of the acrylic resin.

A limitation of this study were the non-reproducibility of the oral environment. In the oral cavity, the denture 
is influenced by saliva, acidic foods, masticatory force, and occlusion of the patient and that mixed microbial biofilms were not assessed. In the oral cavity, microorganisms exist in polymicrobial communities and different species interact in a complex manner to modulate biofilm nature. Future studies should involve other concentrations of RC, as well as other peroxidebased formulations, since the results presented in the literature have been inconclusive. An additional factor to be considered is the importance of simulating the 8-hour immersion period, since it is recommended and routinely used by complete denture wearers. ${ }^{3}$

\section{Conclusion}

Based on the experimental conditions of our study, the $0.2 \%$ sodium hypochlorite solution was effective against the three tested microorganisms, while Efferdent and $6.25 \% R$. communis solutions showed moderate antibiofilm activity against $S$. mutans and $C$. glabrata, respectively. Furthermore, solutions did not significantly alter the acrylic resin properties, after a simulation of five years, as they were considered within acceptable limits.

\section{Acknowledgments}

This study was supported by FAPESP (São Paulo Research Foundation) under grant number [2017/21077-2] and CAPES (Coordination for the Improvement of Higher Education Personnel - Brazil) [Finance Code 001].

\section{Conflict of interest}

The authors declare no conflict of interest

\section{Authors' contributions}

Rocha, Millena Mangueira: Formal analysis (Equal); Investigation (Equal); Methodology (Equal). Carvalho, Adrianne Moura: Investigation (Equal); Methodology (Equal). Coimbra, Flávia Cristina Targa: Investigation (Equal); Methodology (Equal). Arruda, Carolina Noronha Ferraz: Writing-original draft (Equal). Oliveira, Viviane de Cassia: Data curation (Equal); Writing-original draft (Equal). Macedo, Ana Paula: Data curation (Equal); Formal analysis (Equal). Silva, Cláudia Lovato da: Writing-review \& editing (Equal). Pagnano, Valeria: Validation (Equal); Writing-review \& editing
(Equal). Paranhos, Helena de Freitas Oliveira: Conceptualization (Equal); Funding acquisition (Equal); Project administration (Equal); Writing-review \& editing (Equal).

\section{References}

1- Coulthwaite L, Verran J. Potential pathogenic aspects of denture plaque. $\mathrm{Br}$ J Biomed Sci. 2007;64(4):180-9. doi: 10.1080/09674845.2007.11732784

2- Mousa MA, Lynch E, Kielbassa AM. Denture-related stomatitis in new complete denture wearers and its association with Candida species colonization: a prospective case-series. Quintessence Int. 2020;51(7):554-65. doi: 10.3290/j.qi.a44630

3- Axe AS, Varghese R, Bosma M, Kitson N, Bradshaw DJ. Dental health professional recommendation and consumer habits in denture cleansing. J Prosthet Dent. 2016;115(2):183-8. doi: 10.1016/j. prosdent.2015.08.007

4- Vieira AP, Senna PM, Silva WJ, Del Bel Cury AA. Long-term efficacy of denture cleansers in preventing Candida spp. biofilm recolonization on liner surface. Braz Oral Res. 2010;24(3):342-8. doi: 10.1590/ s1806-83242010000300014

5- Freitas Fernandes FS, Pereira-Cenci T, Silva WJ, Filho AP, Straioto FG, Del Bel Cury AA. Efficacy of denture cleansers on Candida spp. biofilm formed on polyamide and polymethyl methacrylate resins. J Prosthet Dent. 2011;105(1):51-8. doi: 10.1016/S0022-3913(10)60192-8 6- Salles MM, Badaró MM, Arruda CN, Leite VM, Silva CH, Watanabe E, et al. Antimicrobial activity of denture cleanser solutions based on sodium hypochlorite and Ricinus communis: a randomized clinical study. J Appl Oral Sci. 2015;23(6):637-42. doi: 10.1590/1678-775720150204 7- Andrade IM, Andrade KM, Pisani MX, Silva-Lovato CH, Souza RF, Paranhos HF. Trial of an experimental castor oil solution for cleaning dentures. Braz Dent J. 2014;25(1):43-7. doi: 10.1590/01036440201302327

8- Sousa Porta SR, Lucena-Ferreira SC, Silva WJ, Del Bel Cury AA. Evaluation of sodium hypochlorite as a denture cleanser: a clinical study. Gerodontology. 2015;32(4):260-6. doi: 10.1111/ger.12104 9- Peracini A, Regis RR, Souza RF, Pagnano VO, Silva CH, Paranhos HF. Alkaline peroxides versus sodium hypochlorite for removing denture biofilm: a crossover randomized trial. Braz Dent J. 2016;27(6):700-4. doi: 10.1590/0103-6440201600913

10- Badaró MM, Salles MM, Leite VMF, Arruda CNF, Oliveira VC, Nascimento $C D$, et al. Clinical trial for evaluation of Ricinus communis and sodium hypochlorite as denture cleanser. J Appl Oral Sci. 2017;25(3):324-34. doi: 10.1590/1678-7757-2016-0222

11- Salles MM, Oliveira VC, Souza RF, Silva CH, Paranhos HF. Antimicrobial action of sodium hypochlorite and castor oil solutions for denture cleaning: in vitro evaluation. Braz Oral Res. 2015;29(1):1-6. doi: 10.1590/1807-3107BOR-2015.vol29.0104

12- Paranhos HF, Davi LR, Peracini A, Soares RB, Lovato $\mathrm{CH}$, Souza RF. Comparison of physical and mechanical properties of microwavepolymerized acrylic resin after disinfection in sodium hypochlorite solutions. Braz Dent J. 2009;20(4):331-5. doi: 10.1590/s010364402009000400012

13- Davi LR, Peracini A, Ribeiro NQ, Soares RB, Silva CH, Paranhos $H F$, et al. Effect of the physical properties of acrylic resin of overnight immersion in sodium hypochlorite solution. Gerodontology. 2010;27(4):297-302. doi: 10.1111/j.1741-2358.2009.00336.x 14- Peracini A, Davi LR, Queiroz Ribeiro N, Souza RF, Silva-Lovato $\mathrm{CH}$, Paranhos HF. Effect of denture cleansers on physical properties of heat-polymerized acrylic resin. J Prosthodont Res. 2010;54(2):78-83. doi: 10.1016/j.jpor.2009.11.004 
15- Pisani MX, Silva CHL, Paranhos HF, Souza RF, Macedo AP. The effect of experimental denture cleanser solution Ricinus communis on acrylic resin properties. Mat Res. 2010;13(3):369-73. doi.org/10.1590/ S1516-14392010000300015

16- Paranhos HF, Peracini A, Pisani MX, Oliveira VC, Souza RF, SilvaLovato $\mathrm{CH}$. Color stability, surface roughness and flexural strength of an acrylic resin submitted to simulated overnight immersion in denture cleansers. Braz Dental J. 2013;24(2):152-6. doi: 10.1590/01036440201302151

17- Arruda CN, Sorgini DB, Oliveira VC, Macedo AP, Lovato $\mathrm{CH}$, Paranhos HF. Effects of denture cleansers on heat-polymerized acrylic resin: a five-year-simulated period of use. Braz Dent J. 2015;26(4):404-8. doi: 10.1590/0103-6440201300120

18- Badaró MM, Salles MM, Arruda CNF, Oliveira VC, Souza RF, Paranhos $\mathrm{HF}$, et al. In vitro Analysis of surface roughness of acrylic resin exposed to the combined hygiene method of brushing and immersion in Ricinus communis and sodium hypochlorite. J Prosthodont. 2017;26(6):51621. doi: $10.1111 /$ jopr.12436

19- Peracini A, Andrade IM, Oliveira VC, Macedo AP, Silva-Lovato $\mathrm{CH}$, Pagnano VO, et al. Antimicrobial action and long-term effect of overnight denture cleansers. Am J Dent. 2017;30(2):101-8.

20- Arruda CNF, Salles MM, Badaró MM, Oliveira VC, Macedo AP, SilvaLovato $\mathrm{CH}$, et al. Effect of sodium hypochlorite and Ricinus communis solutions on control of denture biofilm: a randomized crossover clinical trial. J Prosthet Dent. 2017;117(6):729-34. doi: 10.1016/j. prosdent.2016.08.035

21- Arruda CN, Salles MM, Badaró MM, Sorgini DB, Oliveira VC, Macedo $A P$, et al. Evaluation of biofilm removal and adverse effects on acrylic resin by diluted concentrations of sodium hypochlorite and Ricinus communis solutions. Gerodontology. 2018;35(3):246-53. doi: 10.1111/ger. 12348

22- Arruda CNF, Salles MM, Oliveira VC, Macedo AP, Silva-Lovato CH, Paranhos HF. Using denture cleansers to control biofilm from dentures and brushes: a randomized crossover clinical trial. Int J Prosthodont [Internet]. Forthcoming 2021 [cited 2021 May 5]. Available from: https://doi.org/10.11607/ijp.6665 doi: 10.11607/ijp.6665

23- Paranhos HF, Silva-Lovato $\mathrm{CH}$, Souza RF, Cruz PC, Freitas-Pontes $K M$, Watanabe $E$, et al. Effect of three methods for cleaning dentures on biofilms formed in vitro on acrylic resin. J Prosthodont. 2009;18(5):42731. doi: 10.1111/j.1532-849X.2009.00450.x

24- Dhamande MM, Pakhan AJ, Thombare RU, Ghodpage SL. Evaluation of efficacy of commercial denture cleansing agents to reduce the fungal biofilm activity from heat polymerized denture acrylic resin: an in vitro study. Contemp Clin Dent. 2012;3(2):168-72. doi: 10.4103/0976237X.96820

25- Lucena-Ferreira SC, Ricomini-Filho AP, Silva WJ, Cury JA, Del Bel Cury AA. Influence of daily immersion in denture cleanser on multispecies biofilm. Clin Oral Investig. 2014;18(9):2179-85. doi: 10.1007/s00784-014-1210-9

26- Nishi Y, Seto K, Kamashita Y, Kaji A, Kurono A, Nagaoka E. Survival of microorganisms on complete dentures following ultrasonic cleaning combined with immersion in peroxide-based cleanser solution. Gerodontolology. 2014;31(3):202-9. doi: 10.1111/ger.12027
27- Coimbra FC, Salles MM, Oliveira VC, Macedo AP, Silva CH, Pagnano $\mathrm{VO}$, et al. Antimicrobial efficacy of complete denture cleansers. Am J Dent. 2016;29(3):149-53.

28- Valentini-Mioso F, Maske TT, Cenci MS, Boscato N, Pereira-Cenci T. Chemical hygiene protocols for complete dentures: a crossover randomized clinical trial. J Prosthet Dent. 2019;121(1):83-9. doi: 10.1016/j.prosdent.2017.12.022

29- Paranhos HD, Coimbra FC, Salles MM, Oliveira VC, Macedo AP, Pagnano VD, et al. In vitro evaluation of the effectiveness of alkaline peroxide solutions in reducing the viability of specific biofilms. Am J Dent. 2019;32(4):201-7.

30- Souza RF, Silva-Lovato $\mathrm{CH}$, Arruda CN, Regis RR, Zanini AP, Longo $\mathrm{DL}$, et al. Efficacy of a propolis solution for cleaning complete dentures. Am J Dent. 2019;32(6):306-10.

31- Duyck J, Vandamme K, Muller P, Teughels W. Overnight storage of removable dentures in alkaline peroxide-based tablets affects biofilm mass and composition. J Dent. 2013;41(12):1281-9. doi: 10.1016/j. jdent.2013.08.002

32- Iseri U, Uludamar A, Ozman YK. Effectiveness of different cleaning agents on the adherence of Candida albicans to acrylic denture base resin. Gerodontology. 2011;28(4):271-6. doi: 10.1111/j.17412358.2010.00379.x

33- Kumar MN, Thippeswamy HM, Raghavendra Swamy KN, Gujjari AK. Efficacy of commercial and household denture cleansers against Candida albicans adherent to acrylic denture base resin: an in vitro study. Indian J Dent Res. 2012;23(1):39-42. doi: 10.4103/09709290.99036

34- Amin F, Iqbal S, Azizuddin S, Afridi FI. Effect of denture cleansers on the color stability of heat cure acrylic resin. J Coll Physicians Surg Pak. 2014;24(11):787-90

35- Segundo AL, Pisani MX, Nascimento C, Souza RF, Paranhos HF, SilvaLovato $\mathrm{CH}$. Clinical trial of an experimental cleaning solution: antibiofilm effect and integrity of a silicone-based denture liner. J Contemp Dent Pract. 2014;15(5):534-42. doi: 10.5005/jp-journals-10024-1575 36- Pinelli LA, Montandon AA, Corbi SC, Moraes TA, Fais LM. Ricinus communis treatment of denture stomatitis in institutionalised elderly. J Oral Rehabil. 2013;40(5):375-80. doi: 10.1111/joor.12039

37- Castro DT, Valente ML, Agnelli JA, Silva CH, Watanabe E, Siqueira $\mathrm{RL}$, et al. In vitro study of the antibacterial properties and impact strength of dental acrylic resins modified with a nanomaterial. J Prosthet Dent. 2016;115(2):238-46. doi: 10.1016/j.prosdent.2015.09.003 38- Figuerôa RM, Conterno B, Arrais CA, Sugio CY, Urban VM, Neppelenbroek KH. Porosity, water sorption and solubility of denture base acrylic resins polymerized conventionally or in microwave. J Appl Oral Sci. 2018;26:e20170383. doi: 10.1590/1678-7757-2017-0383 39- Machado AL, Breeding LC, Vergani CE, Cruz Perez LE. Hardness and surface roughness of reline and denture base acrylic resins after repeated disinfection procedures. J Prosthet Dent. 2009;102(2):11522. doi: 10.1016/S0022-3913(09)60120-7

40- Tuna SH, Keyf F, Gumus HO, Uzun C. The evaluation of water sorption/solubility on various acrylic resins. Eur J Dent. 2008;2(3):1917. 